\title{
Child Care Friendly Policies and Integration of ECEC in Taiwan
}

\author{
Chih-Peng Chiu \\ Taipei Municipal University of Education \\ Suechun Wei \\ HungKuand University
}

Taiwan

\begin{abstract}
The aims of this article are fourfold. Firstly, the article outlines the development of the ECEC policy in Taiwan, with a principle focus on female labor force participation rates and birth rates. Secondly, it describes the different types of ECEC services in Taiwan, discussing the process of their evolution and related statistics from a historical perspective. Thirdly, it introduces two important policy initiatives undertaken in the last decade, both of which are suggestive of either a) a political paradigm shift or, b) a transformation of the role of government in Taiwan. One is "woman/family friendly policies" or policies reconciling work and family, which also include maternity and paternity leaves, parental leave, flexible working hours as well as family leave; and the other are a number of "child care friendly policies", comprising subsidies for infant care, an early childhood education voucher program, and the Free Tuition Education Project for 5 year old Children. Finally, the authors provide a general introduction of the ECEC integration policy in Taiwan together with an analysis of possible implications resulting from the implementation of the ECEC Act.
\end{abstract}

Key words : maternity and parental leaves, infant care subsidy, preschool education voucher, ECEC integration policy, ECEC Act, Taiwan

\section{Introduction}

The term Taiwan, also known as the Republic of China (the ROC) and "Formosa", refers to the main island of the Taiwanese archipelago (the other islands include the Penghu islands, Orchid Island, Green Island, and Hsiao Liuchiu), which comprises about $99 \%$ of the jurisdiction of the country. The

Correspondence concerning this article should be addressed to Chih-Peng Chiu, Ph.D, Professor, Department of Early Childhood Education, Taipei Municipal University of Education, No.1, Ai-Guo West Road, Taipei City, 10042, Taiwan (R.O.C.). and Suechun Wei, Ph.D, Associate Professor, Department of Child Care and Education, HungKuand University, No. 34 Chung-Chie Road, Sha Lu, Taichung City 443, Taiwan. Electronic mail be sent to khoo.jp@msa.hinet.net area of Taiwan island itself is nearly 36,000 square kilometers; this is composed of a $1139 \mathrm{~km}$ coastline around the island; its north-south length is about $395 \mathrm{~km}$, with an east to west width of approximately $144 \mathrm{~km}$, the shape often being likened to a long sweet potato. Besides the Taiwan archipelago itself, the islands of Kinmen, Matsu, and Wuchiu (amongst others) which lie across the Taiwan Strait are also administered by the ROC.

Taiwan's current population is approximately 23.2 million, about $98 \%$ of whom are of Han Chinese ethnicity; the other $2 \%$ of the inhabitants are listed as of Taiwanese indigenous origins, a group which can be further divided into $14 \mathrm{sub}$ groups. The Han Chinese immigrants are generally identified as two major groups: 
1) The "benshengren", literally "home-province person" in Chinese, are often referred to as the descendants of the early Han Chinese immigrants, (who in turn are composed of two subgroups, the Hoklo people, making up about $70 \%$ of the total population, and the Hakka, making up about $15 \%$ of the total population. This group and indigenous Taiwanese are also known as "native Taiwanese" in English.

2) The "Waishengren", literally "out-of-province person" in Chinese, comprise $12 \%$ of the population, refers to those who emigrated from mainland China after the Chinese Civil War with the KMT government, and their descendants.

\section{The Development of the ECEC Policy-Context and Background}

\section{Increasing female workforce participation rates}

Female participation rates in the workforce are one of the key factors that affect child care services and the development of the ECEC policies. Stated bluntly, if a woman with pre-school age children chooses to enter the labor market, she has to face the dual challenges of juggling employment and child care. Therefore, the demand for child care services expands alongside increases in the female participation rates in the workforce. As can be seen in Figure 1 (see also Table 1), the labor force participation rate of women aged 25-44 has shown a consecutive upward trend over the past three decades in Taiwan; it rose to $76.51 \%$ (2010) from $41.62 \%$ (1980), an increase of nearly 35\%. More women entering the labor market is seen as being an inevitable aspect of contemporary modern society. In fact, a woman participating actively in the labor market is not only perceived as being a form of personal actualization for the woman herself, but is also something which is seen to have a positive effect on family finances and social economic development.

The issues associated with reconciling work and family issues have been of concern to all developed countries in the international community, and Taiwan is no exception. A number of papers related to this subject have been published here, including reports translated from different languages as well as studies done by Taiwanese researchers. A variety of solutions have been frequently suggested, among them are maternity and paternity leave, parental leave, family leave, flexible working hours, universal approaches to child care, and enhancing the quality of care quality, amongst other measures. Some of the selected "woman/family friendly

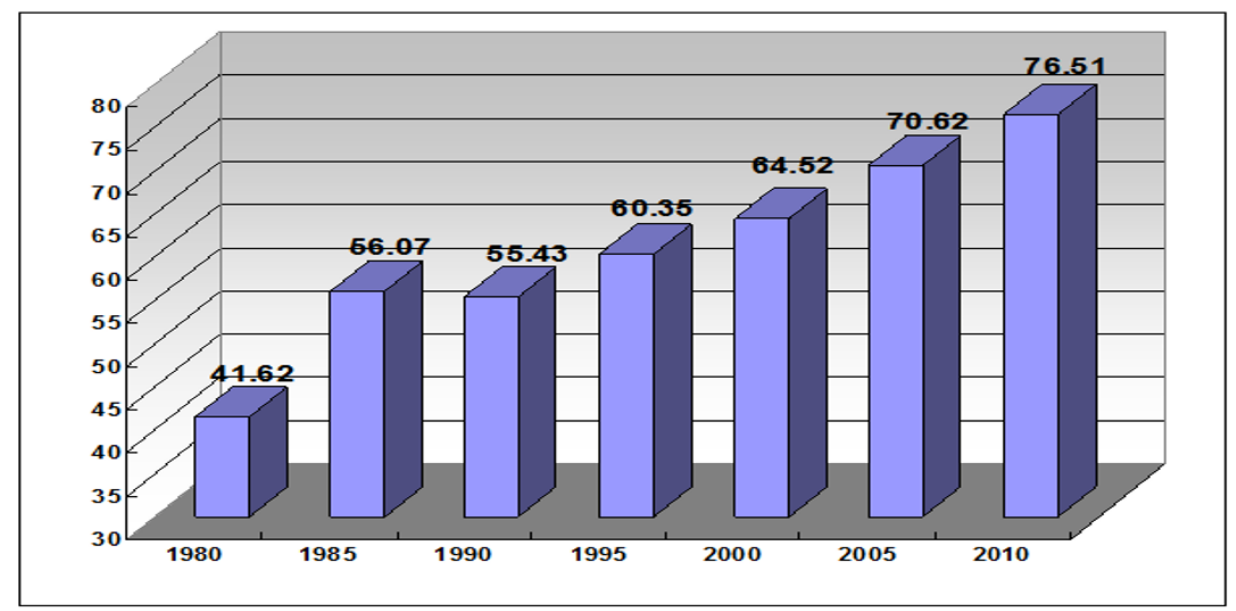

Figure 1. Female labor force participation rate (25-44 year-old) of Taiwan from 1980 to 2010 
policies" and "child care friendly policies" that have been implemented in the last decade in Taiwan will be outlined later in this paper.

\section{Declining in the birth rate}

The birth rate, or the numbers of new babies born each year, is another factor affecting the development of child care services and ECEC policies. From the perspective of the childcare market, it is not difficult to understand, that a high birth rate will create a stronger market demand for child care services. In contrast, a declining birth rate will also cause the childcare market to shrink. In Taiwan, the number of newborn babies has

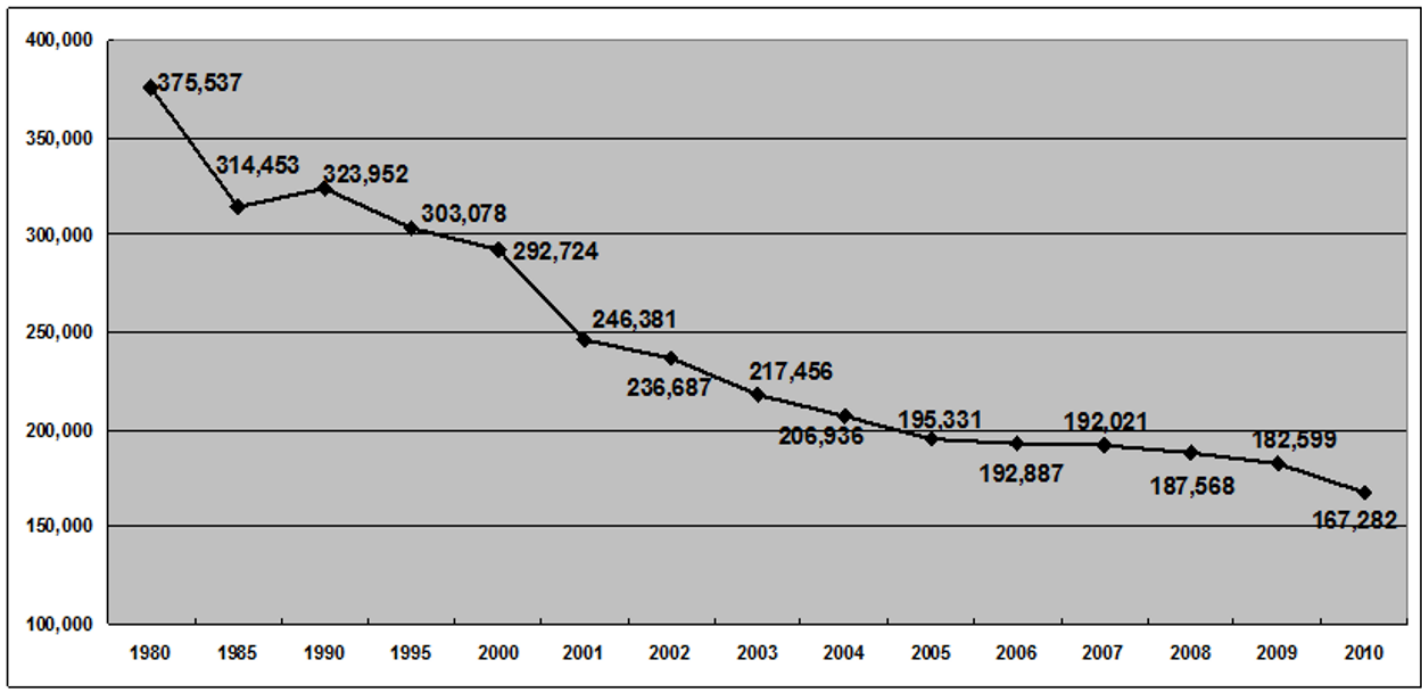

Figure 2. Numbers of newborn babies in Taiwan from 1980 to 2010

Table 1

Population, number of newborns, birth rate and labor force participation rate of women aged 25-44 with the years

\begin{tabular}{cccccccccc}
\hline Years & $\begin{array}{c}\text { Total } \\
\text { Population }\end{array}$ & $\begin{array}{c}\text { AGE } \\
\mathbf{( 0 - 2})\end{array}$ & $\begin{array}{c}\text { AGE } \\
\mathbf{( 2 - 6 )}\end{array}$ & $\begin{array}{c}\text { AGE } \\
\mathbf{( 6 - 1 2})\end{array}$ & $\begin{array}{c}\text { AGE } \\
\mathbf{( 0 - 1 2})\end{array}$ & $\begin{array}{c}\mathbf{0 - 1 2} \text { by } \\
\text { total \% }\end{array}$ & $\begin{array}{c}\text { Nof } \\
\text { newborns }\end{array}$ & $\begin{array}{c}\text { Birth } \\
\text { Rate }\end{array}$ & $\begin{array}{c}\text { women in } \\
\text { work }\end{array}$ \\
\hline $\mathbf{2 0 1 0}$ & $\mathbf{2 3 , 1 6 2 . 1}$ & $\mathbf{3 5 2 . 2}$ & $\mathbf{8 2 0 . 5}$ & $\mathbf{1 , 5 3 8 . 8}$ & $\mathbf{2 , 9 7 8 . 9}$ & $\mathbf{1 2 . 9}$ & $\mathbf{1 6 7 . 3}$ & $\mathbf{1 . 0 1}$ & $\mathbf{7 6 . 5 1}$ \\
\hline 2009 & $23,119.8$ & 381.4 & 839.5 & $1,587.4$ & $3,131.6$ & 13.5 & 182.5 & 1.03 & 75.58 \\
\hline 2008 & $23,037.0$ & 393.0 & 860.8 & $1,682.8$ & $3,259.0$ & 14.1 & 187.6 & 1.05 & 74.83 \\
\hline $\mathbf{2 0 0 5}$ & $\mathbf{2 2 , 7 7 0 . 4}$ & $\mathbf{4 1 3 . 6}$ & $\mathbf{1 , 0 3 7 . 1}$ & $\mathbf{1 , 8 4 3 . 5}$ & $\mathbf{3 , 6 2 0 . 7}$ & $\mathbf{1 5 . 9}$ & $\mathbf{1 9 5 . 3}$ & $\mathbf{1 . 1 2}$ & $\mathbf{7 0 . 6 2}$ \\
\hline $\mathbf{2 0 0 0}$ & $\mathbf{2 2 , 2 7 6 . 7}$ & $\mathbf{5 7 5 . 2}$ & $\mathbf{1 , 2 3 8 . 9}$ & $\mathbf{1 , 9 3 7 . 0}$ & $\mathbf{4 , 0 9 2 . 8}$ & $\mathbf{1 8 . 4}$ & $\mathbf{2 9 2 . 7}$ & $\mathbf{1 . 6 8}$ & $\mathbf{6 4 . 5 2}$ \\
\hline 1995 & $21,357.4$ & 623.8 & $\mathbf{1 , 3 0 2 . 4}$ & $\mathbf{1 , 9 6 9 . 7}$ & $4,272.4$ & 20.0 & 303.0 & 1.78 & 60.35 \\
\hline $\mathbf{1 9 9 0}$ & $\mathbf{2 0 , 4 0 1 . 3}$ & $\mathbf{6 3 9 . 6}$ & $\mathbf{1 , 3 1 8 . 5}$ & $\mathbf{2 , 3 6 4 . 1}$ & $\mathbf{4 , 7 2 4 . 1}$ & $\mathbf{2 3 . 1}$ & $\mathbf{3 2 4 . 0}$ & $\mathbf{1 . 8 1}$ & $\mathbf{5 5 . 4 3}$ \\
\hline 1985 & $19,313.8$ & 678.9 & $\mathbf{1 , 5 9 4 . 8}$ & $\mathbf{2 , 3 5 2 . 1}$ & $4,984.9$ & 25.8 & 314.4 & 1.88 & 56.07 \\
\hline $\mathbf{1 9 8 0}$ & $\mathbf{1 7 , 8 6 6 . 0}$ & $\mathbf{7 8 5 . 7}$ & $\mathbf{1 , 5 7 7 . 5}$ & $\mathbf{2 , 2 2 2 . 1}$ & $\mathbf{4 , 9 7 1 . 0}$ & $\mathbf{2 7 . 8}$ & $\mathbf{3 7 5 . 5}$ & $\mathbf{2 . 5 2}$ & $\mathbf{4 1 . 6 2}$ \\
\hline
\end{tabular}

Note. Population Unit; thousand, Women in work means labor force participation rate of aged 25-44 
declined rapidly over the past three decades; as described in Figure 2 (see also Table 1), the numbers of newborn infants has dropped almost every year.

As indicated in Table 1, there were about 375,500 babies born in 1980, and after 20 years (in 2000), the number dropped to 292,700 , a decrease of $22.0 \%$. During the same period, the fertility rate dropped to 1.68 from 2.52. In the past decade, this situation not only failed to improve but became more serious; to 2010, the number of infants born as well as the birth rate both dropped to 167,300 and 1.01 respectively, compared to the year of 2000, down $46.3 \%$ and .67 , respectively.

Table 1 also lists some relevant statistics from the past few decades, including the total population as well as the number of children at different age levels. These statistics reveal the following :

1) The total population increased, nevertheless, the population growth curve seems to have gradually gone flat in recent years (see also figure 3).

2) The number of children at different age groups shown in table 1 has shown a downward trend, without exception.

3) In addition, the percentage of children under 12 years of age dropped to $12.9 \%$ by 2010 , a reduction of nearly $15 \%$, compared with $27.8 \%$ in
1980.

It may be worth mentioning at this point that the trend in female workforce participation rates (showing an upward trend) and the birth rate (showing a downward trend) are moving in exactly opposite directions. Put into statistical terms, these two factors are negatively correlated. This statistical relationship may imply that seeing these changes from the point of view of demand only is unable to explain the functioning of the child care service market, especially when two influential factors are in conflict with each other. This suggests that we may need to take into account more other influential factors, such as ECEC related policies or public investment trends.

For instance, two well-known international organizations, the OECD and UNESCO, have reviewed and published the ECEC policy implementation experiences of selected countries. These national reports suggested that through appropriate public investments in early childhood education and child care services, a "woman/ family or child friendly environment" could be created; and in consequence, this could become one of the most effective ways to maintain women's labor force participation rates and to raise birthrates

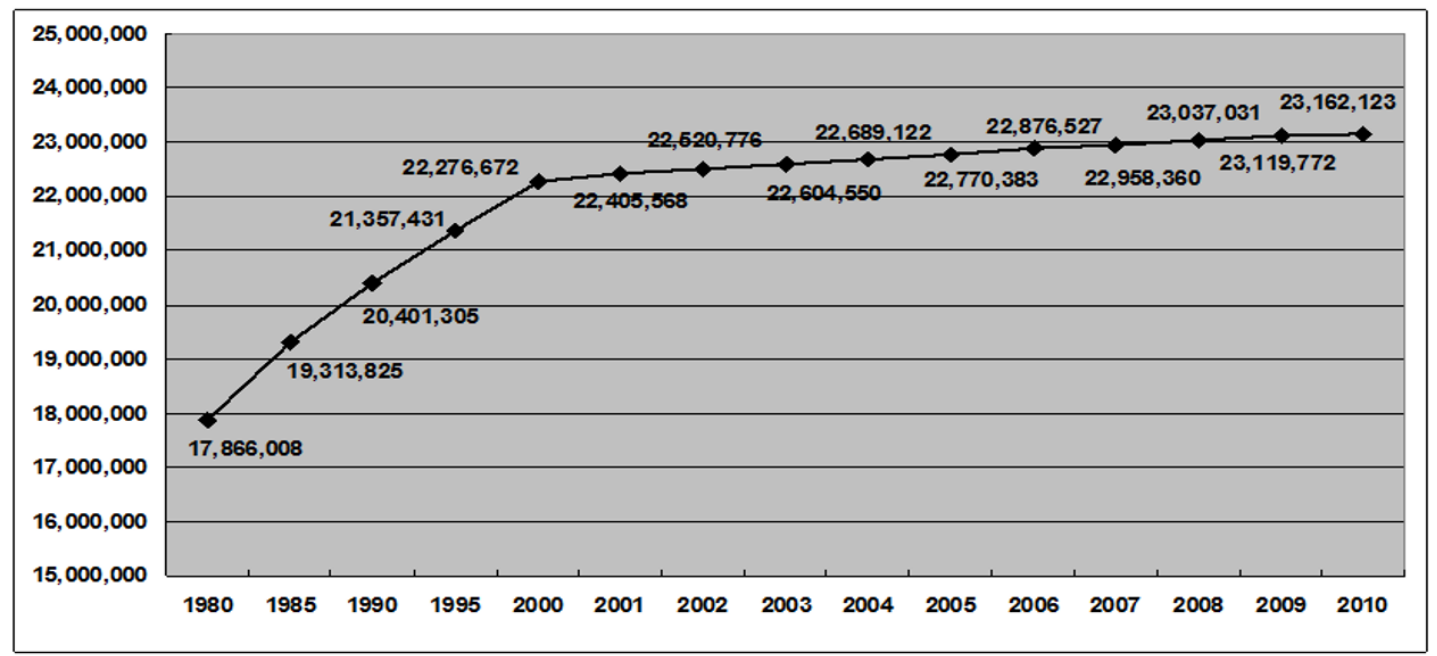

Figure 3. Population growth curve in Taiwan from 1980 to 2010 
at the same time.

\section{A Few Reflections on the crisis of declining birth rates: Taiwan at a Turning Point of a Paradigm Shift}

Although the decline in birth rates will cause many social problems, this crisis could in turn offer an opportunity for policymakers and stakeholders to reconsider "how to encourage young couples to have children." Taiwan is now in such a position. In fact, the situation of a declining birthrate has aroused great concern among the Taiwanese authorities. In January 2011, President Ma Ying-jeou publicly expressed the opinion that birthrate related issues have threatened the country in many ways; a declining birthrate crisis has even been contextualized at the level of national security. Thus, he instructed relevant government departments to organize an across-agency team, committed to deliberating upon effective countermeasures. For this reason, since the beginning of this year, the question of "what is the appropriate role of the government" in child rearing and child care service has been discussed on several different occasions.

In the view of the authors, at present, the development of Taiwan's ECEC policy seems to stand at a crossroads, pondering about how to take the next step; left or right, or a third way. More specifically, the issues under discussion range from the fundamental political ideologies of the government to the specific contents of public policies. At the conference table, such as the following questions are often the focus of debate:

1) Whether or not the government should share with parents the expenses of child rearing and child care. If the government decides to do so, then, what proportion should be shared, and how should subsidies be decided upon?

2) Whether the government should expand public investment in child care service. If the government decides to do so, then, should public funding be used for the demand-side or the supply-side, or distributed to both?
3) What approaches would be selected to expand the supply of child care services, adopting market approaches, building a public service system, or through public-private partnerships approaches? Considering this issue from the position of cost-effectiveness and feasibility, which approach would be better?

4) What requirement should be set to improve child care quality, including the qualification of teachers and caregivers, maximum sizes of a class, child-adult ratios, standards of facilities and equipment, etc.?

In short, debates on the solutions to the low birthrate crisis have concentrated on expanding public investment. The policies proposed included child allowances, child care subsidies, and building a public child care system, etc.

\section{Background Information of ECEC Services in Taiwan}

In the same way as many countries around the world, early childhood education and child care services in Taiwan have been managed by two separate government departments for a very long time. Preschool education and childcare are respectively under the auspices of education and welfare authorities; however, due to the promulgation of the 《Early Childhood Education and Care Act (ECEC Act)》, the administration of ECEC will be changed from the beginning of 2012.

\section{Auspices and Provision of Preschool Education (Kindergarten)}

\section{Auspices}

The Ministry of Education (MOE) is in charge of preschool education, which provides early learning experiences for children 4 to 6-years old, since compulsory education starts from age 6 , up to 15 , for a total of nine years. Kindergarten is a single 
type of education facility in the school system, it is now regulated by the 《Kindergarten Education Act》 (first promulgated in 1981) and its associated sub-laws. Nevertheless, starting from 2012, it will be regulated under the ECEC Act.

Tracing back to the Japanese colonial era (1895-1945) and the early period of the ROC (KMT) government having relocated to Taiwan (1949), only a few ECEC facilities have been established. In fact, before 1970, Taiwan was virtually an agricultural society; only double-income families had such needs, and wealthy families with financial means were able to afford and utilize ECEC services.

\section{The Policies of Public Kindergarten: Public Investment in} ECEC

Almost all public kindergartens in Taiwan were affiliated with the common elementary schools, only a few were affiliated with the experimental elementary schools of teacher colleges. Before 1962, public kindergartens, established by elementary schools, could receive support from the government, and the source of this funding was almost entirely from the budget for compulsory education. This support did not fully cover the necessary costs for preschool education; therefore, parents had to pay a tuition fee, formulated by the County or City Government, to make up the difference in expenditure. In this case, the public kindergarten can be interpreted being one whereby the government and parents shared the costs of preschool education.

The use of government funds in school affiliated kindergartens was prohibited in 1962, because preschool children were not eligible to receive compulsory education budget support. Accordingly, the elementary affiliated kindergartens had to transform themselves into self-sufficient pre-schools, and became "affiliated independent kindergartens". After this change, a number of public kindergartens were closed; those still in operation required parents to fully and evenly share the running costs. The fees paid by parents in this case may be regarded as a "fair market price."

Actually, schools or the competent authorities did in fact make contributions to the affiliated independent kindergartens; they provided free space and the existing facilities. Therefore, in a certain sense, the independent kindergartens affiliated with elementary schools are similar to a public-private partnership pre-school, providing not for-profit early childhood education services to parents. For the purposes of encouraging the establishment of affiliated independent kindergartens, in 1973, The Taiwan Provincial Government ${ }^{2}$ promulgated the" Pilot Program Directions for Independent (Non-funded) Kindergartens Affiliated with Elementary Schools", which allowed schools to utilize the remaining space or empty classrooms for preschool education.

In 1986, a new policy was proposed, which came accompanied by a simple slogan to remind the public of its objectives, "to establish at least one public kindergarten in each township, and one public nursery center within each village". The government funding support was resumed with the implementation of this project. However, public kindergartens and nursery centers at this time were not free of charge; parents had to pay a flat rate stipulated by city or county administrations, usually a partial contribution to the costs. In this context, public investment includes the provision of sites; facilities and subsidies (share balances).

\section{The Provision of Preschool Education}

Following the implementation of this policy, the number of public kindergartens began to increase.

As shown in table 2, for example:

2 This government authority was no longer existence, following the government organization restructuring in 1998. 
Table 2

Numbers of kindergarten, class, and attendances of children by public/private sector with the years

\begin{tabular}{|c|c|c|c|c|c|c|c|c|c|}
\hline \multirow{3}{*}{ Years } & \multicolumn{9}{|c|}{ Numbers of Kindergarten, class, and children enrolled } \\
\hline & \multicolumn{3}{|c|}{ Public sector } & \multicolumn{3}{|c|}{ Private sector } & \multicolumn{3}{|c|}{ Total } \\
\hline & Kinder & Class & Children & Kinder & Class & Children & Kinder & Class & Children \\
\hline 2010 & 1,560 & 3,076 & 72,027 & 1,723 & 6,416 & 111,874 & 3,283 & 9,492 & 183,901 \\
\hline 2009 & 1,553 & 3,062 & 72,991 & 1,601 & 6,540 & 109,058 & 3,154 & 9,602 & 182,049 \\
\hline 2008 & 1,544 & 3,051 & 73,329 & 1,651 & 6,769 & 112,339 & 3,195 & 9,820 & 185,668 \\
\hline 2007 & 1,528 & 3,110 & 73,224 & 1,755 & 7,063 & 118,549 & 3,283 & 10,173 & 191,773 \\
\hline 2006 & 1,507 & 3,036 & 73,334 & 1,822 & 7,246 & 128,481 & 3,329 & 10,282 & 201,815 \\
\hline 2005 & 1,474 & 3,166 & 69,186 & 1,877 & 7,547 & 155,033 & 3,351 & 10,713 & 224,219 \\
\hline 2004 & 1,348 & 2,811 & 73,177 & 1,904 & 7,418 & 163,978 & 3,252 & 10,229 & 237,155 \\
\hline 2003 & 1,358 & 2,772 & 74,462 & 1,948 & 7,645 & 166,464 & 3,306 & 10,417 & 240,926 \\
\hline 2002 & 1,331 & 2,900 & 76,382 & 1,944 & 7,333 & 164,798 & 3,275 & 10,233 & 241,180 \\
\hline 2001 & 1,288 & 2,827 & 75,956 & 1,946 & 7,317 & 170,347 & 3,234 & 10,144 & 246,303 \\
\hline 2000 & 1,230 & 2,776 & 73,434 & 1,920 & 7,258 & 169,656 & 3,150 & 10,034 & 243,090 \\
\hline 1997 & 1,009 & 2,234 & 60,918 & 1,768 & 6,513 & 169,863 & 2,777 & 8,747 & 230,781 \\
\hline 1995 & 883 & 1,968 & 55,529 & 1,698 & 6,677 & 184,839 & 2,581 & 8,645 & 240,368 \\
\hline 1990 & 696 & 1,655 & 47,388 & 1,809 & 6,457 & 189,897 & 2,505 & 8,112 & 237,285 \\
\hline 1987 & 639 & 1,601 & 47,569 & 1,879 & 6,769 & 202,610 & 2,518 & 8,370 & 250,179 \\
\hline 1986 & 550 & 1,331 & 41,188 & 1,846 & 6,552 & 197,240 & 2,396 & 7,883 & 238,428 \\
\hline 1985 & 158 & 553 & 17,859 & 2,052 & 7,115 & 216,815 & 2,210 & 7,668 & 234,674 \\
\hline 1983 & 525 & 954 & 33,809 & 1,394 & 5,408 & 180,267 & 1,919 & 6,362 & 214,076 \\
\hline 1981 & 382 & 1,015 & 48,784 & 903 & 3,796 & 142,909 & 1,285 & 4,811 & 191,693 \\
\hline 1980 & 404 & 1,065 & 44,934 & 782 & 3,527 & 133,282 & 1,186 & 4,592 & 178,216 \\
\hline 1975 & 273 & 651 & 29,342 & 489 & 2,145 & 88,648 & 762 & 2,796 & 117,990 \\
\hline 1973 & 267 & 491 & 22,492 & 414 & 2,004 & 88,485 & 681 & 2,495 & 110,977 \\
\hline 1970 & 218 & 567 & 25,560 & 352 & 1,508 & 66,424 & 570 & 2,075 & 91,984 \\
\hline 1965 & 201 & 534 & 24,143 & 354 & 1,299 & 54,735 & 555 & 1,833 & 78,878 \\
\hline 1962 & 277 & 668 & 29,536 & 337 & 1,223 & 48,362 & 614 & 1,891 & 77,898 \\
\hline 1960 & 353 & 766 & 35,863 & 322 & 1,117 & 43,839 & 675 & 1,883 & 79,702 \\
\hline 1955 & 297 & 607 & 28,503 & 116 & 432 & 17,887 & 413 & 1,039 & 46,390 \\
\hline 1951 & 177 & 410 & 7,735 & 26 & 100 & 3,796 & 203 & 510 & 21,531 \\
\hline 1950 & NA & NA & NA & NA & NA & NA & 28 & 397 & 17,111 \\
\hline
\end{tabular}

Note. NA; number not available 
In 1985, the number of public kindergartens stood at 158 , with 17,859 students enrolled in 553 classes (an average of about 113 students per kindergarten, with 32 children per class).

- By 1990, the number of public kindergartens grew to 696 (an increase of over four times in five years), with 1,665 classes and 47,388 students enrolled (an average of about 68 students per kindergarten, with 29 children per class).

- By 2000, the number of public kindergartens grew to 1230, with 2,776 classes and 73,434 children registered (an average of about 60 students per kindergarten, with 27 children per class).

- By 2010, it grew further to 1560 public kindergartens, with 3,076 classes, attended by 72,027 children (an average of about 46 students per kindergarten, with 24 children per class).

An increasing number of public kindergartens $(1,560-1,230=330)$ in the past decade (please refer to table 2, 2000 and 2010 statistics) had not brought a corresponding increase in school enrollment. On the contrary, the children's attendance was decreased $(72,027-73,434=-1,407)$.

Furthermore, while a total number of public kindergartens increased 330, the number of classes was increased by only $300(3,076-2,776=300)$. The impact of low birth rate might be a reasonable explanation of this fact. Despite the actual statistics, it definitely should not be regarded as a cost-effective public investment: "While the investment is increasing in the number of public kindergartens and classes, the results are showing reduction in school attendance."

There are at least two ways to estimate the effectiveness of investment in public kindergartens. We may adopt the statutory class size $3^{3}$ (that is 30

3 By the 《Kindergarten Education Act (KEA), the maximal children) or the averaged class size of 2010 (that is 24 children), as the base, and using the following formula to calculate profit and loss:

\section{"Real changed number" minus "should be increased number"}

Suppose that each one of the new kindergartens created in the past decade has only a single class, the sum of the children enrolled in the kindergarten should theoretically increase to $9900(30 \times 330)$, or $7920(24 \times 330)$, despite the classes lost from other established public kindergartens. In this case, the "Real changed number" is " - 1470", and "should be increased number" is "+9900" or " $+7920 "$ " Therefore, the total difference is " $-1470-9900$ $=-11,307$ " or " $-1470-7920=-9,327$ ".

If we focus only on the increase of kindergarten classes in the past decade, the sum of children enrolled in kindergarten should increase 9000 (30 × $300)$, or $7200(24 \times 300)$.

In this case, the "Real changed number" is "1470", and the "number which it should have increased to" is "+9000" or " $+7200 "$ ". Therefore, the total difference is " $-1470-9000=-10,407$ " or " $-1470-7200=-8,670 "$.

These differences are by no means indicating that parents cannot afford it, as opposed to "for-profit" private kindergartens, public kindergartens in fact charge less. Some local investigations have indicated that public kindergartens were better than their private counterparts in many respects, including the percentage of qualified teachers, the salaries and welfare of employees, the appropriateness of the curriculum and instruction, etc., but service hours were shorter and could not meet the needs of parents.

The description above may help us in understanding the history of public kindergartens

capacity per class is 30 children. 


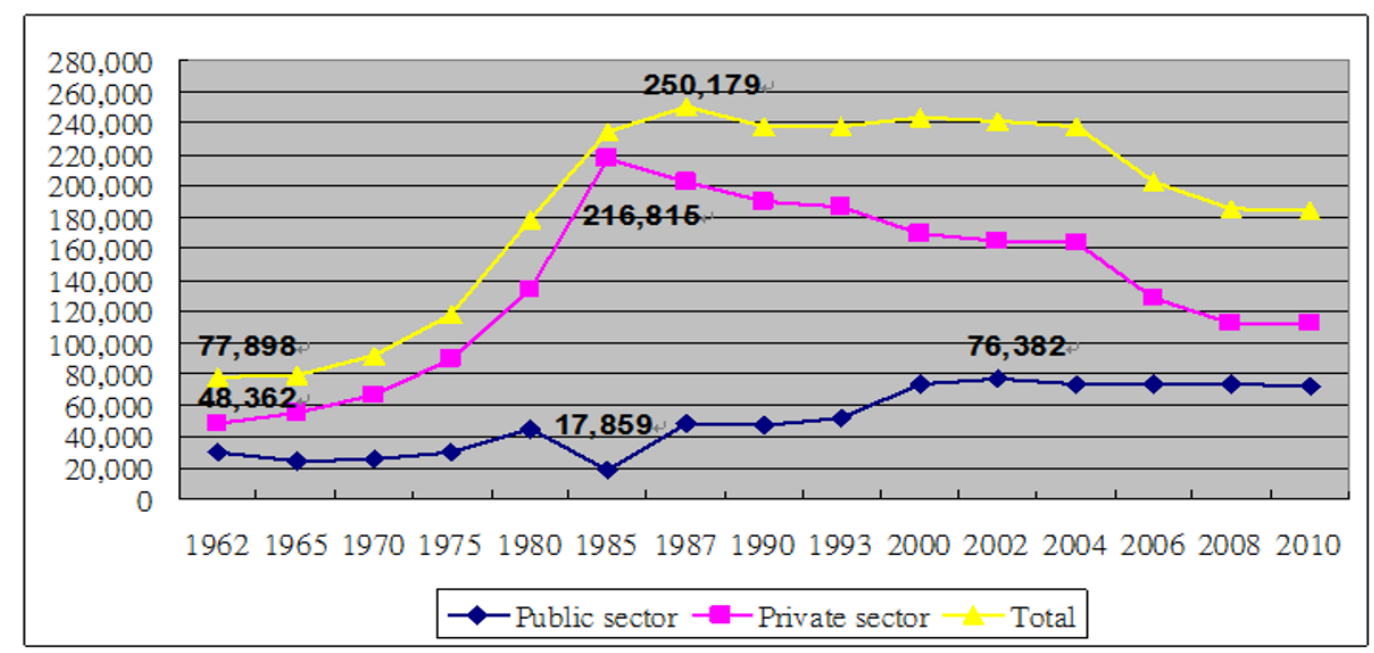

Figure 4. Kindergarten enrollments (public, private, and total)

and related issues in Taiwan. Should we increase investments to public kindergartens? We definitely need to find a way to improve areas of weakness before such investment. Currently there are about 40 "not for-profit" public-private partnerships child care centers; they have the strengths of public and private kindergartens, perhaps this can serve as an alternative to public investment in Taiwan.

As depicted in figure 4, in 2010, the total enrollment in kindergartens stood at 183,901, in which $60.1 \%$ of children were participating in private kindergartens $(111,874)$, and the other $39.9 \%$ in public kindergartens $(72,027)$. The changes in enrollment in the last three decades can be outlined as follows:

1) Private kindergarten enrollment rates reached a peak in 1985; there were 216,815 children taking classes in 2,052 centers. In the same year, there were only 158 public kindergartens, attended by 17,895 students $(7.6 \%)$, less than $10 \%$ of the total enrollment $(234,674)$.

2) The high point of attendance $(76,382)$ at public kindergartens was in 2002, and accounted for 31.7\% of the total enrollment $(241,180)$ the same year.

3) The highest point of the total enrollment $(250,179)$ occurred in 1987 ; in which $81 \%$ of children were attending private kindergartens $(202,610)$, and the other $19 \%$ were attending public kindergartens $(47,569)$.

\section{Child Care Services}

\section{Auspices and Types of Services}

There are three types of center based child care facilities, including:

1) The infant care center (crèche), which serves children from 1 month up to 2 years old, and, according to current regulations, it can be established independently or be affiliated with nurseries. The demand for infant care is strong, and many infant centers are filled to capacity, and some of them have long waiting lists. In 2006, there were 111 independent set infant centers, serving 1,626 young children; by 2010, the total establishment of infant centers was enlarged to 169 (not including those affiliated infant programs), and the attendance of young children at such facilities increased to 3,254, indicating an upward trend.

2 ) The child care center (nursery) serves children from 2 to 6 years old, some of which also provide infant and/or school-age child care (after school) 
services. In the same manner as Kindergartens, the history of nursery services can be traced back to the Japanese colonial era. In the beginning of the 1950s, the Taiwanese government initiated an economic combined welfare policy, called the "busy harvest child care project". This project was aimed at assisting farming families to care for their children during the busy harvest season. The busy harvest nursery system was seasonal in nature; sites used local community centers, meeting houses, or empty school classrooms. This policy received very positive responses, by1956; almost every village had a space for the busy harvest child care system. The first "regulations for the establishment of nursery centers" was enacted in 1955.

Beginning from 1962 to 1971, with the financial assistance of UNICFF (UN International Children's Emergency Fund), each county established a

Table 3

Numbers of childcare center and attendances of children by public/private sector with the years

\begin{tabular}{|c|c|c|c|c|c|c|}
\hline \multirow{3}{*}{ Years } & \multicolumn{6}{|c|}{ Numbers of childcare center and children enrolled } \\
\hline & \multicolumn{2}{|c|}{ Public sector } & \multicolumn{2}{|c|}{ Private sector } & \multicolumn{2}{|c|}{ Total } \\
\hline & Centers & Children & Centers & Children & Centers & Children \\
\hline 2010 & 287 & 59448 & 3,538 & 174,240 & 3,825 & 233,688 \\
\hline 2008 & 312 & 62,942 & 3,696 & 173,518 & 4,008 & 236,460 \\
\hline 2006 & 341 & 74,233 & 3,872 & 191,996 & 4,213 & 266,229 \\
\hline 2004 & 361 & 88,028 & 3,896 & 212,229 & 4,257 & 300,257 \\
\hline 2002 & 392 & 102,568 & 3,505 & 224,557 & 3,897 & 327,125 \\
\hline 2000 & 388 & 106,666 & 2,955 & 202,973 & 3,343 & 309,639 \\
\hline 1998 & 456 & 107,786 & 1993 & 140,731 & 2449 & 248,517 \\
\hline 1996 & 674 & 112,310 & 1548 & 122,657 & 2222 & 234,967 \\
\hline 1995 & 2400 & 120,239 & 1260 & 109,404 & 3660 & 229,643 \\
\hline 1993 & 2415 & 121,695 & 1249 & 108,086 & 3664 & 229,781 \\
\hline 1990 & 2403 & NA & 1342 & NA & 3745 & 238,660 \\
\hline 1987 & 2861 & NA & 1415 & NA & 4276 & 251,502 \\
\hline 1985 & 4049 & NA & 1192 & NA & 5241 & 230,811 \\
\hline 1980 & 2198 & NA & 730 & NA & 2928 & 185,709 \\
\hline 1975 & 1258 & NA & 473 & NA & 1731 & 106,671 \\
\hline 1970 & 744 & NA & 181 & NA & 925 & 97036 \\
\hline 1965 & 158 & NA & 167 & NA & 325 & 141825 \\
\hline
\end{tabular}

Note. NA; Number Not Available, The numbers shown in public sector included village and public nurseries (after 1987); before 1987 included harvest busy and public nurseries 


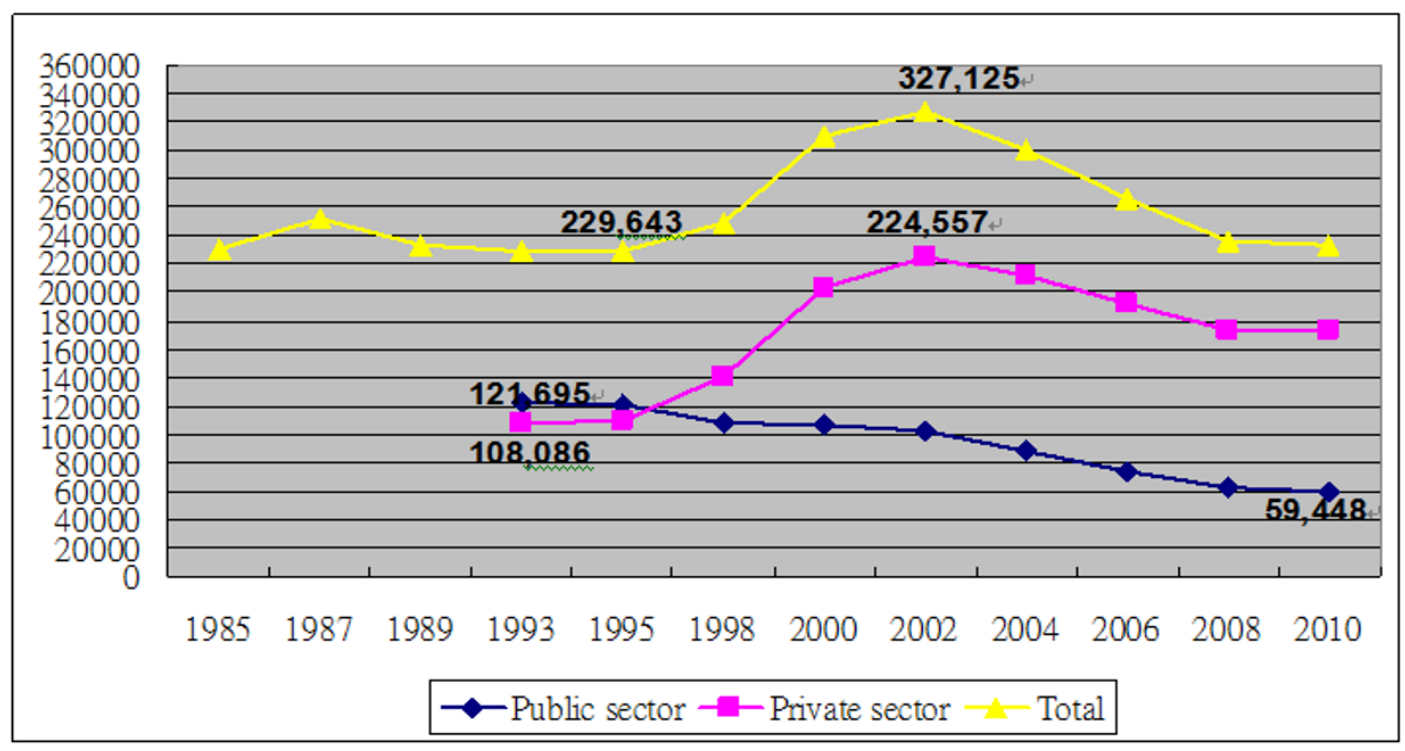

Figure 5. Child care center attendances (public, private, and total)

"village demonstration nursery" to help seasonally busy harvest nurseries to convert into long-term village nurseries. According to the Taiwan Provincial Government's official reports, in 1987, there were 2,828 village nurseries, with an enrollment of 131,000 children.

In 1996, the Taiwanese government initiated a "public nurseries establishment policy", and more than 100 large nurseries were built in the following years, and a number of village nurseries were merged into public nurseries. As shown in table 3, the number of public nurseries had been dropping sharply since 1995.

Table 3 shows that the total attendance in child care centers stood at 233,688 in 2010, among them $74.6 \%$ of children were participating in private sector facilities $(174,240)$, and the other $25.4 \%$ in public sector facilities $(59,448)$. The changes in attendance in the past several decades are shown here (see also figure 5):

- The total enrollment hit the highest point in 2002 (327,125); in the same year, children participating in private child care centers also reached a peak $(224,557)$, up to $68.6 \%$ of the total attendance.

- The highest point of attendance $(121,695)$ at public nurseries was in 1993; this accounted for $53.0 \%$ of the total enrollment $(229,781)$ the same year. On the other hand, there were 108,086 children (47.0\%) attending private child care centers.

3) School-age child care center, also known as after-school child care centers, taking care of children 6 years old and up, can be established independently or affiliated with a nursery. Since 1985, the number of after-school child care centers began to grow rapidly. According to statistics published in 2004, more than $60 \%$ of them were established in urban areas. Until 2002, The Child Welfare Bureau officially classified after-school child care centers as a welfare service institute and listed them as such in annual statistics (a total of 1,015 centers, serving 40,309 school-age children). By 2010, there were 824 after-school child care centers (those affiliated with nurseries were not included), attended by 35,521 children (included children served in the nurseries affiliated school-age child care centers). 


\section{Woman/Family and Child Friendly Policies}

\section{Maternity and Fraternity Leave}

According to related regulations in Taiwan, for example, the 《Gender Equality in Employment Act (GEEA) 》 and the $\ll$ Labor Standards Act (LSA) $\gg 4$, fully paid maternity leave shall be granted to any female worker who has been employed for more than six months. However, if the period of service is less than six months, she shall be paid wages at half of the regular payment. The duration of maternity leave may range from five days to eight weeks. In the case of healthy full term pregnancy, a female worker is entitled to have a combined period of eight weeks maternity leave before and after childbirth. However, in the case of a miscarriage, there are three different types of leaves, depending upon the following situations (GEEA, §15; LSA, §50).

- After the first three months of pregnancy, the female worker shall be permitted to discontinue work and shall be granted maternity leave for a period of four weeks.

- After being pregnant for over two months and less than three months, the female employee shall be granted a maternity leave of one week.

- After being pregnant for less than two months, the female employee shall be granted maternity leave for five days.

For any female worker on any type of maternity leave, if her spouse is employed, the employer shall grant him three days off as paternity leave. During the preceding paternity leave period, wages shall be paid (GEEA, §155).

\section{Parental Leave, Flexible Working Hours and Family Leave}

Any employee, after being in service for one year, has the right to apply for parental leave without

4 The GEEA was first promulgated in 2001; the LSA was first enacted in 1984.

5 The GEEA article 15 was revised in 2007; the fraternity leave was modified from 2 days to three days. pay before any of his/her children reach the age of three years old; the period of this leave is limited to two years (GEEA, §16). After the expiration of the parental leave, employees may apply for reinstatement, and employers may not reject such applications (GEEA, §17). Furthermore, according to the 《Employment Insurance Act (EIA)》, an insured employee (per parent) on parental leave without pay shall be given an allowance for up to six months per child. The amount of this remuneration is $60 \%$ of the insured person's monthly earnings. If both parents are covered by employment insurance, they may apply for the parental leave allowance separately and not at the same time. In the event that there are two or more children requiring care at the same time, the allowance prescribed in the preceding paragraph shall be granted for one child only (EIA, §19-26).

For the purpose of raising children under three years of age, an employee hired by work places with more than 30 employees may ask their employers to reduce their work time by one hour per day (without remuneration) or to adjust their working times (GEEA, §19). In addition, if an employee needs to take care of family members who are suffering from a serious illness, or to handle other major family events, he/she may request family leave. This leave is limited to 7 days per year, and shall be incorporated into normal leave. The computation of wages during the family leave period shall be made pursuant to the related statutes and administrative regulations governing normal leave (GEEA, §207).

6 The EIA was first promulgated in 2002; article 19-2 was a new provision updated in 2009.

7 In 2001, the GEEA article 20 required that employees who are eligible to apply for family leave should be hired by employer employing more than 30 people; this eligibility requirement was revised to employer employing more than 5 people in 2007. It was revised again in 2010, confirming that any employees are entitled to apply for family leave. 


\section{Infant Care Subsidies}

In 2006, under the administration of the DDP government, Taiwan undertook a significant social policy initiative, the "Great Warmth Social Welfare Package Program", in which the "Universal Infant and Child Care System Plan (UICCSP)" was passed by the Executive Yuan meeting in September of the same year. The infant care subsidies policy, first implemented in April 2008, was a part of the UICCSP. This policy adopted a "work-welfare" position, aiming to encourage and assist working parents to resolve employment and child care issues, and to reduce the financial burden of infant care. For this dual purpose, the policy beneficiaries are limited to families with children under 2 years old.

The Child Welfare Bureau, of the Ministry of the Interior is responsible for funding for infant care subsidies, through annual budget procedures. The beneficiaries are divided into two types of family, average and disadvantaged families, as shown in the following Box.

The average families' total annual household income must be less than 1.5 million NT dollars (about 50 thousands in American dollars). Employment is a required condition to obtain infant care subsidies. Accordingly, one or both Parents (guardians) must be employed (by government, schools or public and private institutions; or as LSA referred to, hired by employers and also contribute to labor insurance) to be entitled to subsidies. If neither of the parents is employed, they have no right to receive subsidies. The amount of the subsidies for the average family is 3,000 NT dollars (about 100 American dollars) per month for each infant in care.

Box 1 The Beneficiaries of Infant Care Subsidies

\begin{tabular}{|c|c|}
\hline Disadvantaged Families & Average Families \\
+ & + \\
Employment & Employment \\
\hline
\end{tabular}

\begin{tabular}{|c|c|}
\hline Disadvantaged Families & Average families \\
+ & + \\
Not Employed & Not Employed \\
\hline
\end{tabular}

The families defined as disadvantaged families include the following: low-income families, families with less than 2 years old developmentally delayed or disabled children, high risk families, and families in especially difficult circumstances. Various types of disadvantaged families, in accordance with the relevant laws should provide supporting documents when applying for this designation. All disadvantaged families are entitled to obtain infant care subsidies, regardless as to whether the parents are employed or not. If at least one parent is employed, the subsidy is 5,000 NT dollars per month for each infant in care. In the case where both parents (or guardians) are not employed, while there are temporary child care needs, on condition that they are willing to participate in vocational training or search for jobs; or their families are in special circumstances or have suffered especially unfortunate events, they can be covered. The maximum subsidy is 2,000 NT dollars per month for each infant in temporary care; however, the grant is based on actual hours of child care, at 100 NT dollars per hour. In a sense, this support can be viewed as a tentative form of assistance for families in need.

\section{The Early Childhood Education Voucher Program}

In January 1998, the Taipei City Government enacted "Implementation Directions for Early Childhood Education Vouchers" scheme, and started the first early childhood education vouchers program (ECE Vouchers Program) in Taiwan. Then, in August the same year, the Kaohsiung City Government, responding to public demands, also initiated an "Early Childhood Care and Education Allowances Project (ECCE Allowances Project)" which then began to grant preschool children subsidies. These two programs ceased when the 
Yuan Administration began implementing the "Early Childhood Education Vouchers Scheme (ECE Vouchers Scheme)" in September, 2000.

There are many similarities in the contents of the policies of the Taipei City's ECE Vouchers Program and the Kaohsiung City's ECCE Allowances Project. In terms of the beneficiaries and the amount of subsidies, both were:

- Limited only to five year old children attending a licensed private kindergarten or child care program, located in their respective administrative jurisdictions. Five-year olds enrolled in public ECEC services were excluded for the reason that government already had shared costs partially for these facilities.

- No provisions for "means testing".

- The amount of the ECCE allowance as well as the ECE voucher is 5,000 NT dollars per semester $(10,000 \mathrm{NT}$ per year) for each child.

- Those who were legally identified as disadvantaged and had been given sufficient childcare subsidies (e.g., indigenous, developmentally delayed or disabled children; children of vulnerable families), should not be allowed to receive the same kind of grants repeatedly.

Started shortly after the aforementioned policy was implemented, the issue of equitable distribution of education resources became the subject of serious and passionate public debate, and this also resulted in protests from other cities and counties in Taiwan. In response to the challenges and discontent from all sides, the Yuan Administration ultimately promised to launch a nationwide early childhood education voucher policy. The national ECE Vouchers Scheme was basically an extension of Taipei City's ECE Vouchers Program, the beneficiaries and the subsidy amount is the same as above. The sources of funding were budgeted by the Ministry of Education (responsible for children attending private kindergartens) and the Ministry of the Interior (responsible for children attending private child care centers), respectively. The national ECE Vouchers Scheme was terminated in August 2011, along with the "Free Tuition Education Project for 5 year old Children -" which then came into effect.

\section{The Free Tuition Education Project for 5 year old Children}

Free admission for 5 year olds was one of the political promises in President Ma's 2008 campaign, and it was then changed into the Free Tuition Education Project for 5 year old Children project by the Ministry of Education. This project was first launched in August 2010, however, the first year's policy objects only applied to Indigenous townships as well as areas outside Taiwan Island. ${ }^{8}$ The amended plan, starting from the second year (August, 2011), stated that policy objectives should cover all regions of Taiwan, ROC. According to the MOE, the amended project adopts "quasicompulsory education" as its core concept; the entitlement of free admission to school is deductively explained as the right for tuition-free preschool education. Therefore, providing tuition assistance to 5-year-old children is the main objective of this policy. Besides this, in order to reduce the financial burdens of child care, the project also offers additional grants to relatively low income families.

The policy beneficiaries are defined as: children who are at least five full years of age, attending a public kindergarten or child care center, or enrolled in a "Private Cooperation (Partnership) Program" ${ }^{9 "}$.

8 There are 55 townships listed as aboriginal area in Taiwan, 30 mountain villages and 25 plain towns; areas outside Taiwan Island comprise 3 counties and 3 township.

9 Private Cooperation (Partnership) Programs include licensed private kindergartens or child care centers which meet specifications of this project and have signed a contract with city or county authorities. 
Table 4

Annual subsidies for different household income groups

\begin{tabular}{|c|c|c|c|c|}
\hline \multirow{2}{*}{$\begin{array}{l}\text { Annual Household Income } \\
\text { Type of Program Attending }\end{array}$} & \multicolumn{2}{|c|}{ Public Sectors } & \multicolumn{2}{|c|}{ Private Sectors } \\
\hline & $\begin{array}{c}\text { Tuition-free } \\
\text { subsidy }\end{array}$ & $\begin{array}{l}\text { Additional } \\
\text { grants }\end{array}$ & $\begin{array}{c}\text { Tuition-free } \\
\text { subsidy }\end{array}$ & $\begin{array}{l}\text { Additional } \\
\text { grants }\end{array}$ \\
\hline Below NT \$300,000 & NT $\$ 14,000$ & \multirow{2}{*}{ NT \$20,000 } & NT \$30,000 & NT $\$ 30,000$ \\
\hline NT \$300,001-500,000 & NT \$14,000 & & NT \$30,000 & NT \$20,000 \\
\hline NT \$ 500,001-700,000 & NT $\$ 14,000$ & NT \$ 12,000 & NT \$30,000 & NT \$10,000 \\
\hline Above NT \$ 700,000 & NT $\$ 14,000$ & 0 & NT \$30,000 & 0 \\
\hline
\end{tabular}

The subsidies scheme is illustrated in the following table (see table 4 ).

- Each 5-year-old child participating in pre-school service provided by the public sector can obtain NT dollars 14,000 to cover the annual tuition fees, 7,000 NT dollars per semester being the estimated standard.

- On the other hand, those who attend Private Partnership Programs will receive subsidies of NT dollars 30,000 per year, the estimated standard being 15,000 NT dollars per semester.

- Addition to the aforementioned tuition subsidies, economically disadvantaged children can get additional grants, according to their annual household income (AHI) brackets. Economically disadvantaged children enrolled in public pre-schools can receive an extra grant of 20,000 (AHI below 500,000) or 12,000 (AHI between 500,001 to 700,000), attended private partnership preschools will get an extra grant of 30,000 (AHI below300, 000), 20,000 (AHI between 300,001 to 500,000), or 10,000 (AHI between 500,001 to 700,000 ) NT dollars.

The supporting measures of "the Free Tuition Education Project for 5 year old Children" include the following:

- Increase public investment in the establishment of public kindergartens or classrooms in disadvantaged regions (mountainous areas and islands besides the main island of Taiwan itself), priority given to areas where the supply of pre-school services is insufficient.

- Through subsidizing public private partnership ECEC programs, to increase the establishment of non-profit kindergartens.

- Ensure that economically disadvantaged children are given priority to access public kindergartens.

- Through subsidies to ensure that children of low income families have the opportunity to attend after-school services (weekdays, holidays and summer vacation) provided by public kindergartens.

- Grants for public kindergartens to purchase facilities and equipment to enrich and improve teaching.

- Grants for teachers to participate in professional development activities.

\section{The Integration of ECEC in Taiwan: A Brief History and Commentary}

The integration of early childhood education and care has been promoted internationally since the end of the 1990s. This issue has caused great concern in many countries, including Taiwan; indeed, ECEC integration has been discussed in Taiwan for over a decade. A few months ago, the 
《Early Childhood Education and Care Act》 was passed by the Legislature on $10^{\text {th }}$ of June, 2011, officially enacted by the Taiwanese president on the $29^{\text {th }}$ of June, and will take effect from the first day of January, 2012.

Several terms and abbreviations have been proposed to represent "the integration of early childhood education and child care services". For instance:

- "ECEC" stands for education and care which implicitly places a greater emphasis on education.

- "ECCE" and "ECCD" stands for Early Childhood Care and Education and Early Childhood Care for Development; here, care is key, meaning that care should be the basis of development and education.

- "Educare" combines education and care together; explicitly conveying the message of integration.

\section{The History of Taiwan's ECEC Integration Policy Development}

The following paragraphs provide a brief history of Taiwan's ECEC policy development.

- In 1998, the former prime minister of the Yuan Xiao Wan-chang Administration openly instructed the Education and Welfare administration to cooperatively develop a suitable project to integrate kindergartens and nurseries.

- In 2000, the first version of the "ECEC integrated project (draft)" was released. It proposed a "split model" by age, nursery 0-3, kindergarten 3-6, but was rejected by the Minister of Education.

- In the end of 2000 (under the DPP Administration), the MOE set up an "early education policy consultant group" and resumed ECEC integration policy. In 2001, the "ECEC integration promotion committee" was established, the Ministers of the MOE and the
MOI served as co-conveners. Under this committee $^{10}$, three policy study groups were organized to carry out necessary and related studies.

- At the end of 2002, "the ECEC integrated policy planning report (draft)" was released, and a numbers of consultation meetings and public hearings were held.

- In 2005, the "ECEC integration project Advisory Committee" and 7 working groups was established to deal with related affairs, including forming the legalization group, responsible for preparing the Early Childhood Education and Care Act (draft) ${ }^{11}$. It was decided that the scope of the ECEC ACT should regulate all types of ECEC services for children aged 0-12.

- In 2006, the ECEC ACT (draft) was ready, and public hearings were held. After that, the title of the ECEC Act changed to the "Children Education and Care Act (CEC Act)".

- In 2007, the Yuan administration approved the "Children Education and Care Act (draft)", and officially sent it to the Legislature for deliberation. The full text included 8 chapters, with 71 provisions. However, the "CEC Act" was not on the agenda for that legislative session.

- Going through all the necessary procedures, on $3^{\text {th }}$ of March, 2009, the "Children Education and Care Act (Draft)" was again sent to the Legislature for deliberation. The full text included 8 chapters, with 69 provisions.

Since then, parties in favor of or against the bill started their lobbying activities respectively. In mid-2010, an unexpected turning point occurred in the Procedure Committee of the Yuan Legislature,

10 The author was invited as a member of the committee, and as the convener of the long term planning group.

11 The author was one of the members in legalization group. 
Table 5

Impacts of early childhood education and care act (ECEC Act)

\begin{tabular}{|c|c|c|c|}
\hline & Contents & Before integration & After ECEC Act comes into force \\
\hline \multirow{7}{*}{ 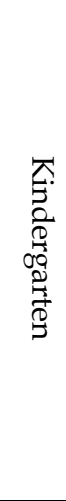 } & Age of children & 4 to 5 -year-old & 2 to 5 -year-old \\
\hline & Auspices & \multicolumn{2}{|c|}{ MOE, The Department of Elementary Education } \\
\hline & Professional & teacher & Teacher, Caregiver, assistant caregiver; \\
\hline & Staffing & 2 teachers/each class & $\begin{array}{l}\text { Should have at least one teacher in each } 5 \text {-year-old } \\
\text { group. } \\
\text { Assistant caregivers should not exceed } 1 / 3 \text { of the total } \\
\text { professionals employed. }\end{array}$ \\
\hline & \multirow{2}{*}{$\begin{array}{l}\text { Child-teacher } \\
\text { ratio }\end{array}$} & 1:15 & 1:15 for 3 to 5 -year-olds \\
\hline & & & 1:8 for 2-year-olds \\
\hline & Maxim.group size & 30 & 30 for 3 to 5 -year-olds 16 for 2 -year-olds \\
\hline \multirow{7}{*}{ 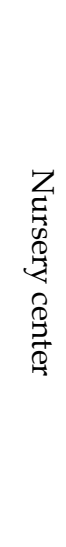 } & Age of children & 2 to 5-year-old & 2 to 5 -year-olds \\
\hline & Auspices & MOI Child Welfare Bureau & MOE, The Department Elementary Education \\
\hline & Professional & Caregiver/assistant caregiver & Teacher, Caregiver, assistant caregiver \\
\hline & \multicolumn{2}{|l|}{ Staffing } & $\begin{array}{l}\text { Should have at least one teacher in each } 5 \text {-year-old } \\
\text { group (should meet this requirement, from the date of } \\
\text { ECEC Act enforcement for five years). } \\
\text { Assistant caregivers should not exceed } 1 / 3 \text { of the total } \\
\text { professionals employed. }\end{array}$ \\
\hline & \multirow{2}{*}{$\begin{array}{l}\text { Child-caregiver } \\
\text { ratio }\end{array}$} & 1:15 for 3 to 5-year-old; & 1:15 for 3 to 5 -year-olds \\
\hline & & 1:12 for 2-year-old & 1:8 for 2-year-olds \\
\hline & \multicolumn{2}{|l|}{ Maxim.group size } & 30 for 3 to 5 -year-olds, 16 for 2 -year-olds \\
\hline \multirow{4}{*}{ 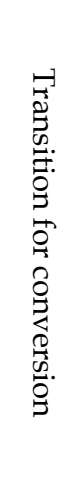 } & \multicolumn{2}{|c|}{$\begin{array}{l}\text { Licensed public and private nurseries (established } \\
\text { independently) }\end{array}$} & $\begin{array}{l}\text { Should convert into kindergartens within } 1 \text { year after } \\
\text { the ECEC Act comes into force }\end{array}$ \\
\hline & \multicolumn{2}{|c|}{$\begin{array}{l}\text { Permitted to set up an affiliated school-age child } \\
\text { care center }\end{array}$} & $\begin{array}{l}\text { Allowed to continue operating SACC, and should } \\
\text { convert into kindergartens within } \mathbf{1} \text { year after the } \\
\text { ECEC Act comes into force }\end{array}$ \\
\hline & \multicolumn{2}{|c|}{$\begin{array}{l}\text { Permitted to set up an affiliated infant center } \\
\text { and/or other services. }\end{array}$} & $\begin{array}{l}\text { Should cease operating infant centers and/or other } \\
\text { services, and convert into kindergartens within } 2 \text { years } \\
\text { after the ECEC Act comes into force }\end{array}$ \\
\hline & \multicolumn{2}{|c|}{ Affiliated to other child welfare institutions } & $\begin{array}{l}\text { Should cease operating within } 2 \text { years after the ECEC } \\
\text { Act comes into force }\end{array}$ \\
\hline \multirow{2}{*}{\multicolumn{3}{|c|}{$\begin{array}{ll}\text { In-home care } & \begin{array}{l}\text { Run by the } \\
\text { sub-laws }\end{array}\end{array}$}} & a; regulated by the Child and Youth Welfare Act and its \\
\hline & & & \\
\hline \multicolumn{2}{|c|}{$\begin{array}{l}\text { School-age } \\
\text { child care }\end{array}$} & $\begin{array}{l}\text { IOI Child Welfare Bureau is in } \\
\text { of community based SACC; } \\
\text { AOE, Department Elementary } \\
\text { tion is in charge of school based }\end{array}$ & $\begin{array}{l}\text { Regulated by the Child and Youth Welfare Act; MOE, } \\
\text { Department of Social Education in charge of both } \\
\text { community and school based SACC, The Department } \\
\text { of Elementary Education is in charge of SACC } \\
\text { affiliated to kindergartens }\end{array}$ \\
\hline
\end{tabular}


when the ruling (KMT) party lawmakers claimed that the "CEC Act" was the idea of the DDP, demanding that it be changed to the "ECEC Act", threatening that it would otherwise be impossible to enter it onto the agenda for that legislative session. The Ministry of Education accepted the compromise, and convinced some scholars and non-governmental organizations to provide some follow up support.

In short, on 10 $10^{\text {th }}$ of June, 2011, the "Early Childhood Education and Care Act" passed as legislation. It comprises 8 chapters and 60 articles. However, the situation returned to the original starting point, the "ECEC Act" integrated only two institutions (kindergartens and nurseries), rather than two systems (early childhood education and child care services).

\section{The Impact of "ECEC Act"}

Table 6 illustrates some of the results or differences before and after "ECEC Act" came into effect.

In addition, the following will also be implemented after the first day of January, 2012:

1) Kindergarten enrolling more than 201 children, should have at least one full-time nursing staff member

2) The maximum group size for 2 to 3 -year-olds should be limited to 16; and shall not be mixed with children of other ages. However, kindergartens set in other islands (besides Taiwan Island itself), remote villages and townships, and indigenous regions, due to the fact that the number of children 2 to 3 years old is few and it is not possible to form a class alone for so few students in this age group, it may report these facts to the governing authorities; an after their approval, may adopt mixed-age groupings with children aged 3 and up, but class size is still limited to 15 children.

3) In other islands (besides the main island of Taiwan Island itself), remote villages and townships, and indigenous regions, where kindergartens are not universally available, may adopt a community mutual cooperative approach to provide early education and care services for young children. The MOE is authorized to make a sub-law to regulate community mutual cooperative types of services.

\section{Reflections on the Integration of ECEC in Taiwan}

A few words, advocating integration, had a deep impact upon the present writer; $\ulcorner$ children do not distinguish their needs based on which agencies run which services - and neither should we.」. This quote above really means we should stand in the child's position and put his interests first as our priority. However, in accordance with the observations and experiences of the current writes, some government officials, lawmakers, providers, and even teachers and caregivers pay more attention to their own interests, rather than the best interests of the child.

Based on the best interests of the child, this paper puts forward the suggestion that the scope of the ECEC integrated policy should deal with two systems, rather than two institutions. Regardless as to which government agency is ultimately responsible for ECEC services, the unification of "early childhood education and child care services" will serve as a solid foundation:

To ensure the integration of professional workers (early childhood teachers, caregivers and other relevant professionals), to provide seamless support to parents or families (a one-stop- service), as well as to deliver a comprehensive and "wrap-around" service to children from birth to 12 years of age, based on their genuine needs.

Reform is most certainly an endless road; the present authors believe that the future will evolve into the success we dream and imagine today, and Taiwan will face these challenges of integration again in the near future. 


\section{References}

Child Welfare Bureau. (2011). Constructing child care friendly environment- Infant care subsidy implementation plan. Retrieved from http://www.cbi.gov. tw/CBI_2/internet/english/index.aspx

Chiu, C. P. (2007). Early childhood education and care integration policy in Taiwan: Policy concepts, planning process and future prospects. Inservice Education, 24(3), 3-22.

Council of Labor Affairs. (2010). Female labor force participation rate. Female labor statistics, Taiwan: CLA.

Department for Education and Skills. (2004). Five year strategy for children and learners: Chapter 2, Early Years, UK: DfES.

Ministry of Education. (2011). 5-Year-Old Children Tuition-Free Education Project. Retrieved from http: //www.edu.tw/secretary/itemize_list.aspx?si te_content_sn=19512

Ministry of Education. (2010). Kindergarten overview Table 1969-2010. Education Statistics, Taiwan: Department of Statistics, MOE.

Ministry of the Interior. (2010). Number of new born and birth rates. Statistical yearbook of interior, Taiwan: MOI.

Ministry of the Interior. (2010). Organization of child care service. Statistical yearbook of interior, Taiwan: MOI.

The Executive Yuan.(2000). Early childhood education vouchers scheme. Taiwan: TYU. 